\title{
Age at menarche in relation to prenatal rainy season exposure and altitude of residence: results from a nationally representative survey in a tropical country - ERRATUM
}

\author{
E. C. Jansen ${ }^{1}$, O. F. Herrán ${ }^{2}$, N. L. Fleischer ${ }^{3,4}$, A. M. Mondul ${ }^{3}$ and E. Villamor ${ }^{3,5}$ \\ doi:10.1017/S2040174416000751, published by the Cambridge University Press, 24 January 2017
}

Unfortunately during the production of this article the wrong affiliations were cited for the listed authors. The corrected affiliations are provided here:

${ }^{1}$ Department of Nutritional Sciences, University of Michigan School of Public Health, Ann Arbor, MI, USA

${ }^{2}$ School of Nutrition and Dietetics, Faculty of Health, Industrial University of Santander, Bucaramanga, Colombia

${ }^{3}$ Department of Epidemiology, University of Michigan School of Public Health, Ann Arbor, MI, USA

${ }^{4}$ Center for Social Epidemiology and Population Health, University of Michigan School of Public Health, Ann Arbor, MI, USA

${ }^{5}$ Center for Human Growth and Development, University of Michigan, Ann Arbor, MI, USA

\section{Reference}

Jansen EC, Herrán OF, Fleischer NL, Mondul AM, Villamor E. Age at menarche in relation to prenatal rainy season exposure and altitude of residence: results from a nationally representative survey in a tropical country. J Devel Orig Health Dis. 2017; 8, 188-195. 